\title{
Value at looking back: Towards an empirical validation of the role of reflexivity in econo-historic backtesting: Economic market prediction corrections correlate with future market performance
}

\author{
Julia M. Puaschunder* \\ The New School, NY, USA; Columbia University, NY, USA
}

\section{ARTICLE INFO}

\section{Article history:}

Received 4 March 2019

Revised 2 December 2019

Accepted 10 December 2019

Published 7 January 2020

\section{Keywords:}

Backtesting

BIP

Business cycles

Central bank communication

Corrections

Errors

Expectations

Forecasting corrections

Gross National Product (GDP)

Globalization

Long boom

Long downturn

Market performance

Price

Reflexivity

\begin{abstract}
The following article innovatively paints a novel picture of the mass psychological underpinnings of business cycles based on information flows in order to recommend how certain communication strategies could counterweight and alleviate information failing market performance expectations that could potentially build disastrous financial market mass movements of booms and busts. An introduction to the history of economic cycles will lead to George Soros' Theory of Reflexivity in order to draw inferences for the analysis of the role of information in creating economic booms and busts in the age of globalization. Empirically, based on a central European central bank's GNP projections and backtesting corrections, a pattern of central bank corrections communication and economic market performance will be unraveled for the first time to outline that central bank market prediction corrections are positively correlated with near future market performances and negatively correlated with distant future market performances. The collective reality of prices and the irrationality of the crowds perturbating markets will be discussed. Business cycles are argued to obey some kind of natural complexity, as for being influenced by econo-historic communication trends. Recommendations how to create more stable economic systems by avoiding emergent risks in communicating market prospects more cautiously will be given in the discussion followed by a prospective future research outlook and conclusion.
\end{abstract}

\footnotetext{
* Financial support of the American Academic Research Conference on Global Business, Economics, Finance and Social Sciences, Fritz Thyssen Foundation, Research Association for Interdisciplinary Studies, The New School Dean's Office, The New School Department of Economics, The New School Fee Board, The New School for Social Research, The New School Eugene Lang College, and the University of Vienna is gratefully acknowledged. The author declares no conflict of interest. All omissions, errors and misunderstandings in this piece are solely the author's
}

* Corresponding author.

E-Mail address: Julia.Puaschunder@newschool.edu

ORCID: 0000-0003-1977-1545 


\section{Introduction}

Globalization led to an intricate set of interactive relationships between individuals, organizations and states (Centeno \& Tham, 2012). Deepening nets of interactions challenge human foresight (Gilpin, 2001). As complex interdependencies may hold unknown outcomes for society, highly integrated international communities are under the whim of unexpected socio-economic developments. In seeking to shed light onto implicit system failures' socioeconomic consequences down the road and potentially-disastrous outcomes of cumulative actions triggering mass movements; the currently emerging Emergent Risk Theory outlines unexpected dangers and insufficiently-described shadows of the invisible hand of the real competition world economy in the age of globalization (Centeno \& Tham, 2012; Miller \& Rosenfeld, 2010).

Since the post-World War period, the world globalized. International economic activities now involve a larger number of countries and sectors than at any time in history and reach deeper into every human life than ever before (Held \& McGrew, 2007). Global interaction possibilities have also made communication unprecedentedly complex. With growing globalization and quickening of transfer speed, information flows may impose unknown systemic economic risks on a global scale (Centeno et al., 2013; Okamoto, 2009; Urry, 2012). Nowadays information flow has no longer limited local effects but potentially unforeseen global consequences (Leonhardt, Keller, \& Pechmann, 2011; Stiglitz, 2006; Summers \& Pritchett, 2012). This paper argues that market performance expectations and information about their burst may create risks within economic markets as for fueling economic booms and downturns. The paper thereby builds on classical theories of prices and the classics' notions of expectations to then embark on heterodox socio-economic concepts such as George Soros' Theory of Reflexivity.

In the light of growing tendencies of globalization, the demand for an in-depth understanding of how information flows echo in socio-economic correlates and may steer economic fluctuations has gained unprecedented momentum. New economic thinking widens the interdisciplinary lens to study emergent risks of international communication shadowing economic markets and the societal compound. In exceeding orthodox economics' insights and traditional public policy attempts to curb societal risks, heterodox economic approaches outlining socio-economics of crises appear as real-world relevant emergent risk prevention strategy. Applying real competition and reflexivity concepts but also the emergent risk theory onto economic fluctuations is an innovative heterodox way to explain how information creates economic ups and downs in a turbulent economic world (Held \& McGrew, 2007).

While by the end of the 1960s, the most renowned economists agreed that recessions were preventable, history proved them wrong (Brenner, 2006). For instance, the period from 1940 to 1973 became renowned for a time of economic prosperity - yet from 1973 a worldwide recession set in. Historic post World War II booms were transitioned to downturn from the mid 1970s on as the economic performance declined in the industrialized world. While in the 1980s and 90s the economy seemed to expand again, from 2000 on productivity slowed, again, from 1998-99 stock markets and currencies crashed or halted in 2001 and 2008. Today, supply-side theory explains the downturn dependent on pressures from labor (Brenner, 2006). Behavioral economists give credit to the unplanned, uncoordinated and competitive nature of capitalist production as well as the problem of aggregates deviating from the individual's choice predictions.

The expectations of outcomes of multiple decisions among people with conflicting interests may not be foreseeable and therefore have been overlooked by stable equilibrium theories. Yet in reality expectations may guide individual decision making and therefore imposed novel risks in complex markets. Economic indicators of product wages, international competition, output-capital ratio, and post-tax profits have been studied extensively to derive conclusions about economic pre-indicators of crises and recommendations for improving economic systems. The role of inflation is widely cited in its invers relation to unemployment to determine economic conditions (Armstrong, Glyn \& Harrison, 1991; Brenner, 2002). International transmissions of inflation are discussed in historic examples to build adaptive expectations on information about current and past experiences with inflation (Soskice, 1978). Disequilibrium inflation is explained in the literature to occur when the actual rate of inflation is greater than the expected followed by social unrest and industrial conflict (Soskice, 1978). Yet in all these discussions, concrete information about economic prospects and the role of economic expectations in shaping ideas and intentions of individual market actors playing out in economic fundamentals is missing. While business cycle theories primarily focus on describing economic correlates of booms and busts such as tight labor markets, investment trends and the uneven development throughout the world causing advantages and disadvantages in the economic impact of booms and busts around the world (Brenner, 2002); less attention is shed on socio-economic correlates that build expectations leading to irrational exuberance. Communication about markets and their performance is yet hereby argued to be underlying long-term economic trends as well. For instance, information transfer is key for innovation and markets to pick up new ideas. Information shaping expectations are the basis of investment trends. Economic 
expectations grown out of information on economic prospects and forecasts guide economic market actions. The collective mood in society shapes investment allocations amalgamating into economic trends that determine economic dynamisms of the collective soul of booms and busts. Economic forecasting and information about economic prospects may trickle down in individual economic decision making, which in its entirety shapes the economy as a whole. Access to information about market performance may also play a key role in price comparisons around the world, which are the basis of outsourcing and capital allocation decisions (Brenner, 2002). Information portrayed in media may also determine the investment mood and credit liquidity preferences of individuals and institutional representatives. Individual communication in the eye of economic ups and downs may in addition be the basis of social unrest and waves of strikes, which have been shown to be underlying factors determining wages and rates of profit for capitalist bleeding into economic cycles (Brenner, 2002). All these correlates set the tact in shaping economic booms and busts as well as the long term cycles. The role of information for economic long-term cycles, however, has been - so far - widely overlooked in the standard neoclassical literature. Communication interventions are neglected in a wealth of writings on Federal Reserve and Central Bank interventions ranging from lowering interest rates to direct monetary stimulus. Studying the effect of information and communication on economic correlates to implicitly influence investment decisions may offer invaluable insights on how bubbles start and economic fluctuations can be smoothed.

The following paper therefore departs from the orthodoxy of hyper-rational individuals, who make rational choices based on perfect knowledge purely self-centered not taking other, history and the governmental issued information into account but makes a case for past performance and backtesting market prediction corrections influencing future performance. While classical economics typically focuses on actual outcomes rather than on the various expectations that might have motivated them (Arestis \& Eatwell, 2008), the presented results will connect expectation performance corrections with future market outcomes.

Through capturing the interplay of communication about prospects and the fundamentals of the economy; the following article is meant to shed light on the socio-psychological underpinnings of economic downfalls. The paper thereby investigates the unprecedentedly described role of information in building and fueling economic booms and downturns. Theoretically, the paper will start with the notion of expectations in classical writings to then draw on historical foundations in economic analysis as outlined in George Soros' (1994) Theory of Reflexivity. Boom and bust patterns will be theoretically described and be argued to have the expected outcomes deviate from the actual path and that the actual path in turn deviates from the underlying fundamentals in reflection of past performances' prediction corrections. This paper will then discuss the impact of central bank forecasting and backtesting actual performance corrections in shaping economic ups and downs. Empirically, a central bank's economic forecasts of the Gross National Product (GNP) followed by publicly published backtesting corrections being related to certain market outcomes will be portrayed as instigation of herd and swarm behavior that potentially caused actual economic booms and busts leading to economic crises. The paper will then discuss the impact of the found future shadows of today's predictions in a heterodox fashion in order to serve as a window of opportunity for alleviating negative externalities of globalization imbued in technocrats' communication about market prospects and outperformed or bust expectations. Pursuing the greater goal of deriving recommendations how to stabilize economic markets in the instant communication century will lead to wider recommendations on finding an optimum balance of deregulated market systems and governmental control.

The following paper is organized as follows: An introduction to the theory of price and history of economic cycles leads to the analysis of the role of information in the creating of economic booms and busts. Economic forecasting and backtesting market correction data of a central European central bank will be presented as for retrieving information on the relation of past performances' corrections and future market outcomes. Recommendations how to create more stable economic systems by avoiding emergent risks imbued in market communication are given in the discussion followed by a prospective future research outlook and conclusion.

\section{Business Cycle Theories}

Recurrent crises are part of capitalism. Economic shocks triggered crises in the 1820s, 1870s, 1930s, and 1970s. The logic of profit drives the system to repeat this pattern, which is inherently turbulent with powerful business cycles. In recent decades, the study of business cycles has moved towards economic fluctuations. Business cycles capture fluctuations in the gross domestic product (GDP). Business cycle studies identify different types of recurrent aggregate fluctuations tied to investments. Business cycles are the most visible elements of the intrinsic dynamics of capitalism, including a fast inventory cycle, a medium term fixed capital and possibly longer structures cycles. Inventory cycles are in the order of three to five years. Equipment cycles range around seven to eleven years. Long 
waves are forty-five to sixty years in duration (Shaikh, 2016). Inventory cycles are linked to balance between demand and supply, while capital equipment fluctuations are traced back to the balance between capacity and actual output. Long-term growth trends feature periods of rapid economic growth in expansions or booms followed by periods of relative stagnation or decline bleeding into economic contractions, busts or recessions. Long waves patterns are found in the price of commodities expressed in gold inspired by Kondratieff.

Business cycles are measured by economic output but also related to the interest rate. Deregulation of financial activities first appears as success. But slowdowns of real wages relative to productivity and a drop in interest rates and in relative real wages boost the net rate of profit. In the build-up to every general economic crisis, the price of gold shoots up relative to the price of other commodities. Booms are greatly enhanced by a sharp drop in interest rates, which raises the net rate of return on capital. Falling interest rates lubricate the spread of capital across the globe, promote a rise in consumer debt and fuel international bubbles in finance and real estate. With falling interest rates and credit being made easier, consumers and other spending continue to rise, buoyed on a rising tide of debt. Crashes occur if people realize that price expectations are not sustainable anyone. A recession is a significant decline in economic activity spread across the economy, lasting more than a few months, normally visible in declining real GDP, real income, employment, and industrial production. Economic depression is characterized by high unemployment and falling prices. Long-run economic patterns in advanced capitalist countries include persistent growth in output, productivity, profits and employment, all taking place in-and-through recurrent cycles and periodic depressions.

Classical economics either denies the existence of business cycles as - for instance in Say's law there is no overor underconsumption - or attributes fluctuations to external shocks such as war, hunger, pandemics and natural disasters. But the inherent character of fluctuations in the economy is a rather heterodox view outlined in Marx (1867/1995), Keynes (1936/2003) and the Austrian economics (Schumpeter, 1949) followed by Soros (2003), Brenner $(2002,2006)$. The relatively unpredictability of the changing seasons of booms and busts calls for a thorough investigation of business cycles embracing heterodox interdisciplinary viewpoints.

Contemporary studies of business cycles and long term waves capture the relation of export, investment and raw materials on economic ups and downs alongside the role of institutions (Armstrong et al., 1991; Brenner, 2002, 2006). Remittances and other credit inter-governmental transfers are vividly described in the literature by historical snapshots. Historical examples of exchange rates pegged to the dollar and the dollar being convertible to gold as well as devaluation strategies are discussed (Armstrong et al., 1991). The Phillips curve invers relation of unemployment and interest rate is unraveled as concomitant of economic waves. Remittances and credit expansions' influence on prices and industrial production are discussed (Armstrong et al., 1991). Shortages and production drivers but also trade association formations were found to play a vital role in shaping the economic climate. In addition, the role of political ideologies determining budget discipline and trade correlates as well as social unionization is thematized (Armstrong et al., 1991). Societal influences - such as working class strikes and tax evasion - play a role in booms or busts (Armstrong et al., 1991). Throughout history - vividly underlined by historical cases of France, Germany and Italy - we can see that booms and busts - through social unrest potential - are also connected and influenced by political ideologies. Central banks and their monetary reform potential are obvious determinants of economic stability. Governmental price control and money circulation means set the tact on the economic status of a nation. The delicate role of war and peacetime recovery is discussed in the economic cycle literature (Armstrong et al., 1991).

By the early 1980s Real Business Cycle Theory (RBCT) developed by retaining the notion of rational expectations and continuous market clearing and adding random productivity shocks to generate aggregate fluctuations that mimicked business cycles. Real business cycle theories attribute technological shocks or political cycles as causes of business fluctuations. The recurrence and turbulent regulation arise quite naturally. Underlying of these longterm patterns is the notion of turbulent regulation, in which balance is only achieved by recurrent over- and undershooting with intrinsic nonlinearities in the process (Shaikh, 2016, p. 8). Endemic turbulent growth is found in US industrial production, real investment and real GNP per capita over periods of 150 years (Shaikh, 2016). There is a recurrence of fluctuations of successive episodes of booms and busts, of overshooting and undershooting, in never ending sequences. Productivity growth is an essential measure of technical change and its steady long-term rise speaks to the fundamental role of technological progress in capitalist development. Technical change is an imperative for capitalist firms, rooted in the very nature of profit-driven competition.

Digging deeper into the causes of business cycles reveals phenomena like overaccumulation and overheating (Armstrong et al., 1991). Overheated growth appears when capitalism generates a higher rate of accumulation than sustainable and investors realize that the expectations do not represent the fundamental price. Imbalances between accumulation and labor supply lead to labor shortages and excess demand for labor, which then lead to a scrapping of old equipment and rise of real wages (Armstrong et al., 1991). Accumulation first drives demand for labor but 
eventually causes a profit squeeze through the scrapping of old plants to speed transfer of workers to new means of production. Accumulation thereby tends to decline gently to a sustainable rate. While overaccumulation was unraveled as one of the underlying future crises onset indicators, in all this the nature of communication behind accumulation leading to a cooling of economic productivity remains unknown. The underlying enthusiasm that first drives profitability and confidence is also not depicted in qualitative terms.

In the case of overheating, prices and wages rise and tighten the labor market, which drives up wages. From there productivity declines and economic prospects become gloom and despondent (Armstrong et al., 1991). Strikes emerge that effect differentials, real wages and profit margins of income (Soskice, 1978). Currencies need to be devaluated in order to remain competitive regarding exports.

In all this available knowledge, the role of information for building business confidence but also to instigate economic fluctuations is unknown. How market communication about economic prospects may accelerate market performance is yet an open research question. Information about how expectations build up in the social compound and how a disconnect of expectations from fundamental values leads to confidence losses and hence capital flight in social networks is missing. While economic stabilization policy using fiscal and monetary policy as well as governmental automatic stabilization appear to mitigate the downsides of cycles or at least dampened the worst excesses of business cycles, little is known about the psychological underpinnings of the global mass psychology of crises and how to use communication to alleviate economic fallouts. While adaptive decision making theory has entered the economics literature, we still have no concrete information on how market expectations' backtestingbased re-evaluation guides individual's choices that amalgamate to the overall economic performance (von Weizsäcker, 2010). Capturing the collective soul of crises, however, could help deriving communication strategies to further counterbalance mass movements as a depression prevention to solve disastrous outcomes of collective moods, herd and swarm behavior on economic markets echoing in the real economy. Key in understanding what drives economic fluctuations based on price expectations appear historical foundations of the theory of price.

\section{George Soros' Theory of Reflexivity}

In the classic tradition, the expected rate of profit is tied to the actual rate of profit similar to Soros' Theory of Reflexivity, which connects expected, actual and fundamental values of economic market systems. One of the most elaborate real-world relevant explanations of business cycles is outlined in George Soros' Theory of Reflexivity. As anticipations of an expected future value in an uncertain world, expectations are a central part of value calculations (Soros, 2000). Expectations are a thought or a belief about anticipated gains or losses, whereby the idea of time is fundamental to rational expectations and outcomes. The subjective expected utility is derived from the value of an outcome and the probability that it will occur. Expectation calculus is used in many domains, including health, wealth, survival and educational outcomes, but likely most prominent in financial realms. While we know that consumers with more optimistic stock market expectations tend to more likely hold riskier assets and acquire stocks in the near future; we still are in need to explore what information and factors drive financial market expectations.

According to Soros (2003), expectations determine prices. To every good and service there is a (1) fundamental value $\mathrm{f}$, what a good is actually worth, when considering the direct market price and price of production and (2) expectations e. When information in markets builds up expectations, expectations start overpromising beyond the fundamental value, therefore e>f. The difference between the expected price and the actual price, Shaikh (2010, 2013) formalizes as the degree of bullishness in the market. People believe a good or service is worth more than its actual fundamental value $f$. The difference between the actual price and the fundamental, Shaikh $(2010 ; 2013)$ refers to as the degree of overvaluation of the market.

Expectations thereby become central to the formation of economic cycles. In an economic cycle, during booms and busts expectations rise or fall, which are triggering cyclical ups and downs.

In the beginning, expectations are gravitated closely to the fundamental value of a good $\mathrm{f}$, outlined in blue in Graph 1.

The nature of the collective soul of booms and busts is outline in Graph 1. 


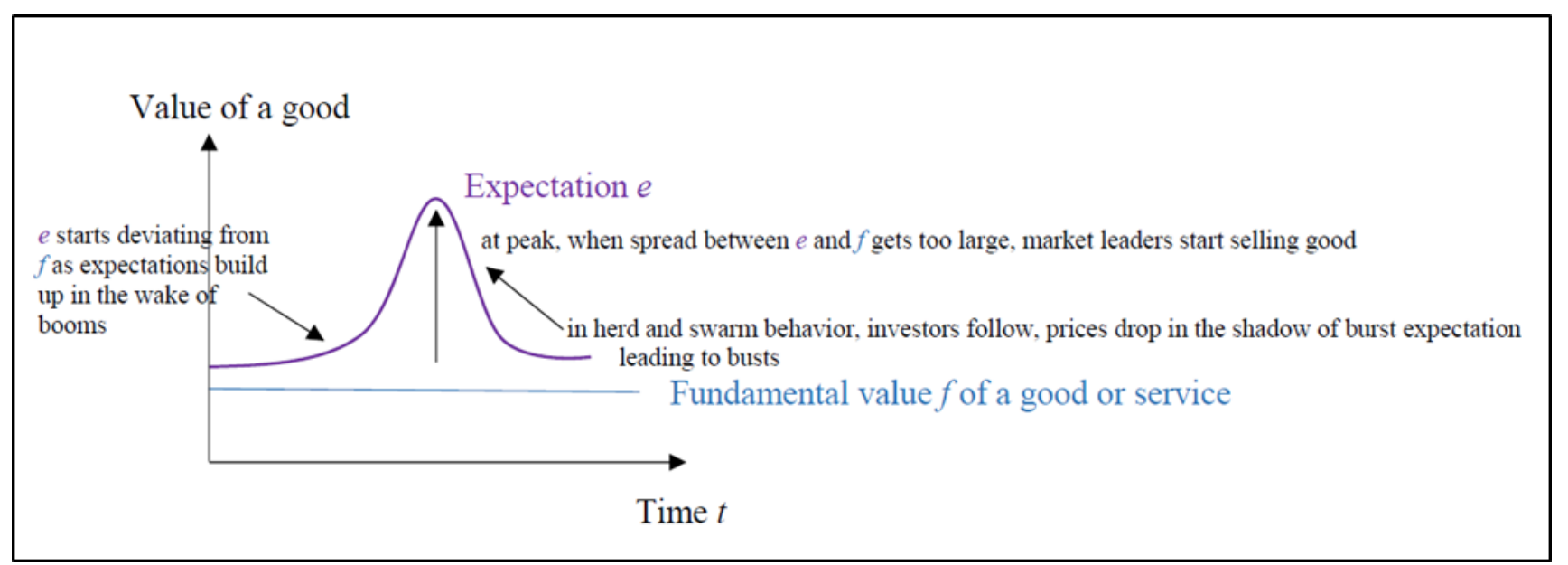

Graph 1. The collective soul of booms and busts

If enough market actors think that the stock will go up, expectations inflate the price. If these anticipations activate enough others to act upon, the expectations rise high above the fundamentals. As information about expectations reaches market actors, it builds up inflated surreal exceptional capital. Positive information serves as self-fulfilling prophecy and social reinforcement lets market investors dream about future anticipated growth. Signalling and positive reputation thereby begin an announced overinflated expectational price, which gets perpetuated in the wake of herd mentality and swarm behavior. The number of buyers rises in expectation of high profits and so the further the expectations get inflated over the real price. Yet as time proceeds and information gets shared, the expectations $\mathrm{e}$, as outlined in purple in Graph 1, build up to the point where the spread between e and $\mathrm{f}$ gets so large that leaders notice this not being sustainable anymore and e having become too detached from the actual true value f. Effects of moods and expectations change if people realize that assumptions are not sustainable. The boom then reaches its peak and first market leaders start selling the good or service off. If e gets largely inflated and majorly detached from f, first market experts start realizing the unsustainable inflation of a good's or services' expected value. The first market actors start losing faith in the product and service, hence trying to sell it. If the amount of sale bids reaches a certain threshold, by the law of supply and demand, the price will eventually decline and then, if animal spirits bleed into a run and more investors follow, eventually inflated prices will collapse. The more the number of people rises that believe that the system is not sustainable as the further one gets away from the real price, the more information gets shared, the more people realize that the bubble bursts. With them setting a vibe in the market, the collective soul of booms and busts naturally triggers herd and swarm behavior of followers, who then start selling the good or service. The price expectations collapse and re-adjust to the actual fundamental value. The economy has then gone from boom (in which e starts building up over f), peak condition (in which there is the largest spread between e over $f$ ) to bust (in which e gets re-adjusted and gravitated back towards f).

Expectations play a vital role in this theory. In the collective soul of booms and busts framework, individual decisions are made by subjective considerations and finance is a process of social outcomes. Confidence in the overall economy is built on overall expectations that can cause higher outputs. Fundamentals are affected by the historically contingent path, which makes the equilibrating process turbulent and path dependent (Shaikh, 2010). Expectations affect actual prices, actual prices affect fundamentals and expectations influence the behavior of actual prices and fundamental prices in a turbulent process, in which actual prices oscillate turbulently around the gravitational values (Shaikh, 2010). Soros' Theory of Reflexivity addresses the process of turbulent meta-physical equalization. Soros' notion of reflexivity holds that if investors think that the price of stock goes up influences others to think the same. Therefore, expectations will be that there is a rising of price that will activate others to follow. If enough people act on it, that alone can drive up the price above its fundamentals. When prices are above fundamentals, people start to realize that this is not sustainable and pull out. Single investors reap a benefit by leaving markets earlier when representative agents stay in markets. As people are betting against each other, some become winners and others losers in financial bubbles. Those lose who expect the process to be long term eternally growing.

A rise in business confidence based on animal spirits raises investment and causes the positive multiplier to rule. Yet unmet expectations are triggering the market to go under. Prices get out of balance not being justified by fundamentals during the building of the bubble. Soros explains how expectations can create an output but also a collapse if they are not validated anytime and are too removed from the fundamentals below them. Shaikh's (2010, 
2013) formalizes Soros' reflexivity mathematically. Similar feedback systems can be found in Goodwin's (1967) predator-prey model.

Soros' (2003) innovative contribution is that expectations can change the fundamentals in creating bubbles and herd mentality and swarm behavior of investors to offset a path to cyclicality (Shaikh, 2013). The actual responds to fundamentals can higher gravity. If the gap between the fundamentals and the actual orbit will grow larger, there will be a reverse effect on the fundamentals. Profit rates may change expectations. If a sufficient number of people expects the price to go up, the price will really go up and create a boom in which expectations are dominating price movements. If the market price is above sustainable levels, more and more people will realize that this is not sustainable, which will lead to short deviations from the fundamentals in contrast to long deviations. Animal spirits will lead markets in disproportion with reality. Expectations' collapse causes a crunch in output and falling employment rates. Depressions cause real wages to rise, moves in direction of free markets making things worse through rising inequality. Problem of crisis stagnate action and send countermovement signals to other industries and markets. In the age of globalization, a crunch in one country leaps over to other territories. Especially if either the EU or US is stuck in depression, the whole world joins. Over the decades, George Soros offered many example applications of his Reflexivity Theory explaining occurrences in world finance, history, and political sciences, which become a function of cognitive and system manipulative tendencies (Kwong, 2008).

Over the business cycle, one can by now predict certain behavior in the wake of dynamic cyclical fluctuation shocks of continuous equilibrating processes. Yet price expectations and economic cycles - to this day - are hard to predict. The actual temporal flow of these recurrent patterns is hard to measure quantitatively. One knows that it will happen but can only guess when it will occur. While there is a pattern of the economy, problems of agents remain to distinguish between noise and information in shocks and change. In the ever-changing nature of capitalism, having evolved from industrialization to post-World War booms to globalization and the new media revolution, the cycles have become more fuzzy and unpredictable.

Already Dobb (1929) commented on the tendency of modern economics to downplay the psychological and qualitative aspects of value creation, yet information on attributed value based on expectations is to this day mainly missing in neoclassical economics (Sen, 2003). While we have insights about the mathematical calculus of the expected value of a discrete random variable being the probability-weighted average of all possible values, mainly estimated as probabilities by frequencies; we lack an understanding of the economic correlates in the wake of sociopsychological phenomena regarding outperformed or burst expectations - leading to feelings of hubris or disappointment. While behavioral economics has established the notion of loss aversion and losses looming larger than gains (Kahneman \& Tversky, 1979); we have no stringent framework on reference point dependence regarding backtesting-based expectations under- or outperformance. To this day, we have no sound information how expectations are built up in markets and how the over- or underperformance creates social norms around markets that may inflate to herd behavior or swarm phenomena. In general, we can assert the higher a person's expectation and the lower the performance, the higher the frustration and trigger of cessation of activity and quitting behavior - yet what this means for financial market decisions, we have no concrete information about. As people develop favorable and unfavorable expectations that guide their choices and behavior on a daily basis, we need to unravel how these expectations influence economic market actors' decisions bleeding into the collective soul of booms and busts.

Expectations play a vital role in economic calculus. Since firms have to produce for the future, any production is based on expectations on future outcomes (Keynes, 1936/2003). Expectations are formed in a dynamic process. Anticipations are skewed and dependent on other people. Expectations influence what happens in the process, as people do not correctly anticipate what will be going on. Soros' (2003) financial market theory holds that some people will belief that market prices will rise forever. They do not know that turn will happen and other do not have a clue when turn will happen. If a sufficient number of people beliefs that the system is not sustainable, the bubble bursts. According to Friedman, surprises in markets matter more than expectations. Every deviation besides surprises are temporary. Information on the expectation performances underlying economic ups and downs could help bridge between rational behavior and societal collective action (Soskice, 1978). Unraveling the impact of expectations and the role of information in building and destroying expectations in financial markets could aid serving the greater goal of fostering sustainable finance - a mandate primarily addressed by central banks and governing financial authorities. Central Banks and market prospects play a crucial role in shaping expectations and correcting over- or undershooting in market predictions. 


\section{Central banks' information and crowd control}

In society, language is used to embody theories of reality. Discourse is inseparable from social and economic factors; yet more needs to be known about the concrete effect of information communicated in markets echoing in economic fundamentals, such as price and equilibrium formation (Fowler, Hodge, Kress \& Trew, 1979). Different social strata and groups but also different institutions and media have different varieties of language available to them. Linguistic variations reflect and actively express the structured social differences, which give rise to inequality and economic dispersion (Orwell, 1949).

Access to information about markets is distributed unequally within society. Certain market actors have faster and more access to aggregate information about prices than others (Benabou \& Laroque, 1992). Access to a different level of aggregate data allows for competitive market advantages. Governments and in particular central banks hold more aggregate information than regular market actors. It is on these actors to utilize information appropriately and their technocrats are obliged to grant the populace access to information. Banking and finance information is usually communicated in the realm of central banks.

Central Banks or Reserve Banks are monetary authority institutions that manage a state's currency, money supply and interest rates. Started from ancient Egypt forerunners, the 1609 founded Amsterdam Wisselbank accounts for the first central bank, which soon led to similar banking institutions in central Europe - featuring notable banks in Hamburg, Venice, Nuremberg, Sweden and England - during the 17th century. The 20th century featured an explosion of central banks around the world, for instance, in 1913 the U.S. Congress enacted the U.S. Federal Reserve, followed by central banks in Australia, Peru, Colombia, Mexico, Chile, Brazil, Canada, India, New Zealand and African and Asian countries. The European Central Bank hosted in Frankfurt Germany was established in 1998.

Historically set up to ensure the efficiency of markets and safeguard monetary stability and international trade, central banks oversee the commercial banking system of respective countries or overseen territories. Central banks primarily implement monetary policies by setting the interest rate; manage inflation and exchange rates and controlling a nation's money supply. The main monetary policy instruments available to central banks are open market operations to influence the money supply of an economy, bank reserve requirement, interest rate policy, relending and re-discount via the repurchase market, and credit policy often coordinated with trade policy. As lenders of last resort and manager of foreign exchange, central banks are holders of gold reserves. In cooperation with the legislative and executives bodies of a nation, central banks regulate and supervise the banking industry. Holding the monopoly on controlling the monetary base of a country, central banks are printing and issuing their national currency due to their exclusive Right of Issuance and therefore control the fiat monetary supply. Central banks foster stability of interest rates, financial markets and the foreign exchange. Central banks also aim to control economic growth via the interest rate. Especially during economic downturns lowering the interest rate incentivizes industry borrowing more money to invest to encourage economic growth. Raising the interest rate is often used as means to curb inflated economic growth as a counter-cyclical move to keep the economy from overheating and to avoid market bubbles.

Central banks also have supervisory and regulatory powers to ensure the solvency of member institutions, prevent bank runs and reckless or fraudulent behavior by member banks. Some central banks' mandates include unemployment control. In most developed nations, central banks are institutionally designed to be independent in the operational management from political interference, yet accountability and control by the executive and legislative bodies are usually enacted. As holders of aggregate information about a country's economic status and outlook, central banks play a vital role in the world's economy as for issuing information about markets, primarily focused on economic growth and economic outlook prospect.

People have a right to know in access to information mandates and regulatory discretion that require central banks to publish data about economic forecasts. In doing this, central banks have an elevated role to set incentives and constraints but also build and destroy expectations in market performance in backtesting reporting. In the operationalization of market communication, central bank standards differ. While some banks publish re-adjustments of their forecasting errors, others refrain to do so. These differences even persist in the harmonized and standardized Euro-zone territory, which - to this day - features national central banks besides the European Central Bank.

While there are writings on the role of information to control behavior, little is known about the unintended consequences of information in expectation building and hence bubble creation. Economic uncertainties may partially stem from fluctuations of discourse on outcomes and prospects. Hardly any information exists on the role of central banks in informing citizens about the status of the economy. The paper therefore sets out to study what linguistic structures exist to create realities about prices and markets. Information will be portrayed as a means to regulate the ideas and behaviors of social masses. Contrary to other linguistic analysis of communication, this article does not aim at unveiling the misuse of language by institutional agents to control society but rather seeks to shed 
light on unknown dangers of communication echoing in economic correlates. Information may implicitly aid in building expectations and hence bubbles to add to economic fluctuations. Central bank information is thereby revealed as powerful mode of language and thought. Central bank announcements and economic forecasting mass communication is viewed as a tool to unconsciously drive the economic engine but may also cause disturbance in financial markets. Unprecedentedly described implicit economic fluctuations built by central bank information will become the focus of attention. The media will be portrayed as means to control society's relationship to material reality (Fowler et al., 1979).

What is the driver of equilibrium and what communication causes fluctuations in the economy? The article will show how central bank communication about economic prospects is related to economic outcomes. Contemporary writings address political, institutional and social processes as makers of crises, yet the role of information for the building of economic moods is mainly neglected. Economic prospect information released by central banks is argued to shape individual's expectations and social processes that influence behavior and group outcomes in economic markets bleeding into the collective soul of booms and busts. This article thereby focuses on the unintended and unforeseeable consequences of information on economic forecast corrections in their relation to actual outcomes following the greater goal to gain more certainty about the economic situation in order to breed financial market stability and economic prosperity.

\section{Research question}

While neoclassical economics begins from a perfectionist base and introduces imperfections as appropriate modifications to the underlying theory, the following paper will highlight the role of information for real competition in order to argue for a democratization of information flows. Introducing emergent risk mitigation strategies within globalized economic markets may thus help avert future socio-economic crises and imbue public trust in open market economies through improved economic market stability and societal welfare stemming from universal access to equally shared benefits of global economies.

The following part focuses on representing connections of expectation corrections in backtesting and actual market performance. The paper thereby targets at opening the black box of deliberately future-oriented market prospect reporting and the stylized linear time scale in neoclassical economics, which will be challenged to be disrupted by seasonal information shocks. The paper will show the problem with the neoclassical assumption of perfect information and feature inconsistent representations of information by shedding light on imperfections that produce certain types of outcomes in consumption, equilibrium and price. The paper will thereby outline how the market responds to central bank market communications and how market corrections are related to actual market performance in the near future but also backlash to cyclical tendencies in the more distant future. Attention will be paid to temporal heterogeneity, the information blast moment differing from a linear time scale. On a wider scale, the article will paint a picture of markets behaving in line with corrected market predictions. Acknowledging that agents make choices under social constraints, a dependence of past performance on current actions will be unraveled. Studying information on market prospects will allow constructing a framework of socially structured market fundamentals and derive conclusions how expectation outcomes echo in economics. The importance of historical conditions but also social and cultural structures will be outlined. Thereby an opening of time consistent predictions will allow contributing to non-linear models of predictions and market outcomes paying tribute to the idea of turbulent real economies. Business cycles will be shown to obey some kind of natural complexity; they are whimsical based on socio-historic and political trends as well as follow the occasional madness of actual human behavior. The paper thereby embraces diversity in granting heterodox perspectives of our contemporary knowledge on the formation of business cycles. Overall, the article will connect micro-economic information flows with macro-economic fundamentals and address the emergent properties of heterogeneous agents through the wide varieties of constructions of expectations.

Departing from classical economics addressing exogenous causes for economic cycles, the following paper will focus on unraveling endogenous - thus system-inherent - business cycle drivers. As an alternative to this debate, the following article innovatively paints a novel picture of the mass psychological underpinnings of business cycles in order to recommend certain communication strategies counterweighting the building of disastrous financial market mass movements. As business cycles are a collective phenomenon, group interactions' potential contribution towards business cycles will innovatively be outlined and the role of information flows among groups unraveled. Studying the role of information in communicating crises appears logic when considering that business cycles are fluctuations found in the aggregate economic activity of nations that organize their work. Information will also set the tact on if and how prices become an abstraction determined by ideology shifts. 
The following reflections on the inside of economic ups and downs will introduce psychological elements into economic debates. While economics seem to give clear guidelines on how economic correlates of competition, wage pressure, deregulation and repression of real wage growth play out in economic terms, the irrational exuberance that leads to purchasing and investment decisions in the overestimation of future profit perspectives cannot be explained by orthodox economics. Booms and busts will be portrayed as phenomena that are built by the collective decision making within society as market actors anticipate and panic together. The following empirical part will shed light on communication of economic prospects and information representation of estimates of central banks and capture a novel relation of past market predictions correction with near and distant future market performance.

\section{Method}

In order to test for the relation of information and expectations on markets shaping prices, information about market projections of a central European central bank was retrieved online ${ }^{1}$. This central bank bi-annually publishes the real Gross National Product (GNP) in percentage changes to the previous year (GNP, Bruttoinlandsprodukt Veränderung zum Vorjahr in \% (real) in the original) of a central European country for four years - 1 year retroactively, the year in which the report is issued and the prospect of the following year and the 2-year prospect. The report includes the correction of the former expectation of the GNP in the former calendar year $\mathrm{t}-1$, the same calendar year $\mathrm{t}$ as the report is issued and the prospect about the future year $t+1$ and two years $t-2$ in advance. The information contains the backtesting previous year market performance correction $t-1$, the current year $t$, the following year $t+1$ and the prospect of market performance in two years $\mathrm{t}+2$. Information on such market performance and prospects is available since 1998 until now at the central bank's homepage accessible for anyone with access to the internet. These reports get published twice a year, in June and in December of each year.

The reports offer information about expectations and market prediction corrections. Growth forecast errors have leveraged into a macroeconomic tool to draw inferences about forecasting model weaknesses in order to make better predictions about future market performances (Blanchard \& Leigh, 2013). In the wider sense, forecasting error corrections offer an opportunity to study whether markets move in the direction of announced market corrections.

\section{Results}

In the data analysis, at first the market corrections for each data point representing the real Gross National Product (GNP) of a central European national economy in percentage changes to the previous year were calculated. The market corrections were then plotted in relation to the GNP market performance after the correction in the next half year $\mathrm{t}+1$ and in the next year $\mathrm{t}+2$ period. Graph 2 holds the GNP market performance prediction corrections $\mathrm{c}$ and GNP market performance GDP after correction derived from a central European central bank for the years 1999 to 2017.

\footnotetext{
${ }^{1}$ https://www.oenb.at/Geldpolitik/Konjunktur/prognosen-fuer-oesterreich/gesamtwirtschaftliche-prognose.html
} 


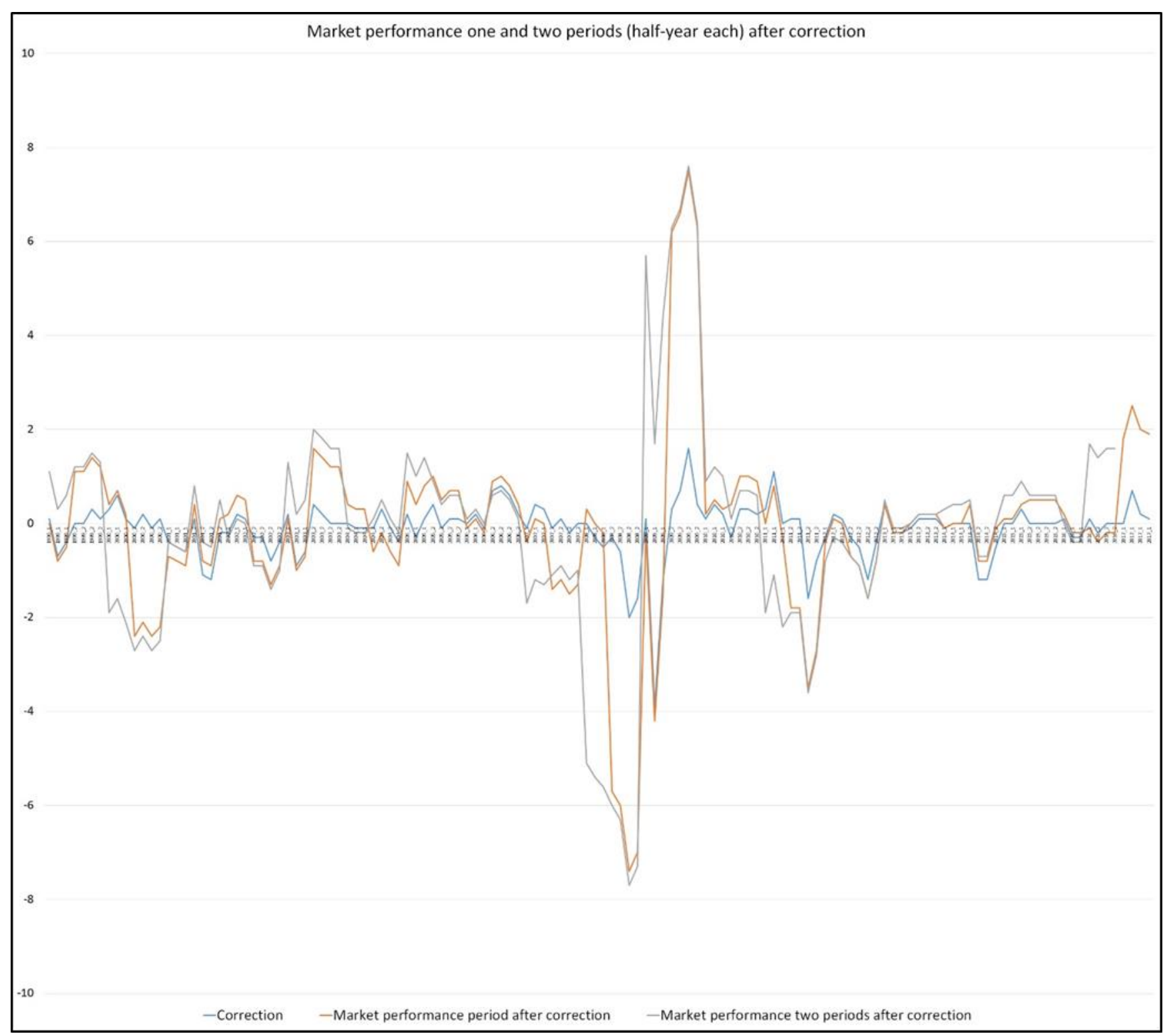

Graph 2. GNP market performance prediction corrections and GNP market performance after correction (years 1999-2018)

The data set-up accounted for the corrections c being enacted retroactively in backtesting - so after the time had passed, hence for example a correction for 1999 as $\mathrm{t}-1$ that was released in $\mathrm{t}$ is the year 2000 - but the market performance trend being real time, so 2000 market performance trends in $2000 \mathrm{as} t+1$. We can thus infer the relation of a correction for the past performance and the future market performance in the half year $(t+1)$ and the year $(t+2)$ thereafter. Market corrections are represented by variations in estimations over time.

A highly significant positive correlation between the overall correction in $t$ and subsequent market performance in the next bi-annual period $\mathrm{t}+1$ (rPearson $(130)=.417, \mathrm{p}<.000)$ was found for the years 1999 to 2017 . A highly significant negative correlation (rPearson $(126)=-.303, \mathrm{p}<.001)$ between the overall correction in $\mathrm{t}$ and subsequent market performance in the period $\mathrm{t}+2$ ranging from half a year after to a year after the initial correction was found for the years 1999 to 2017.

In order to determine whether past period $\mathrm{t}-1$ corrections or current state $\mathrm{t}$ corrections or future prediction corrections $t+1$ and $t+2$ are associated with a certain market trend, correlations were calculated for the association between (1) $t-1$ corrections and $t+1$ actual market performance as well as (2) $t-1$ corrections and $t+2$ actual market performance (3) $t$ corrections and $t+1$ actual market performance as well as (4) $t$ corrections and $t+2$ actual market performance. A significant positive correlation between the correction in $\mathrm{t}-1$ and subsequent market performance in the next bi-annual period $\mathrm{t}+1$ (rPearson(37)=.353, $\mathrm{p}<.032$ ) was found for the years 1999 to 2017. A highly significant negative correlation between corrections in $t$ and subsequent market performance in the next period starting after half a year up to a year after the announcement $t+2$ (rPearson(37)=-.633, p<.00) was found for the years 1999 to 2017. 
Overall, retroactive backtesting market corrections are highly significantly positively correlated with the following market performance. Corrections of past periods are positively correlated with current performances in the near future but negatively correlated with future performances in the more distant future. Current period announcements are associated with positive trends in the subsequent period up to half a year after the announcement and negative trends in the period following more than half a year later to a year later. Past market performance shapes the future prospect and expectations about markets.

In order to consolidate the findings and determine the interaction of variables and length of the effect, two regressions were calculated based on the following equation 1 and 2 :

$$
\Delta \mathrm{Y} \_(i, \mathrm{t}+1)=\alpha+\beta \_1 \quad \mathrm{~F} \_(\mathrm{i}, \mathrm{t}-1)+\beta \_2 \mathrm{~F} \_(\mathrm{i}, \mathrm{t})+\varepsilon_{-}(\mathrm{i}, \mathrm{t}) \text {, }
$$

(Equation 1)

whereby Y represents GDP and Y_(i,t:t+1) GDP growth in percent from the current period in the following half year periods $t+1$, representing a half year interval between $t$ and $t+1$.

Growth forecast corrections are calculated by the difference between actual real GDP percentage changes during one period $\mathrm{t}$, based on the latest data, minus the forecast prepared for the period under scrutiny presented in the previous period $t-1$. F_( $i, t)$ is the forecast error correction in GDP growth for the given periods of $t$. The associated forecast error correction is $F_{-}(i, t: t)=\left\{Y_{-}(i, t) \mid \Omega_{-} t\right\}$, where $Y_{-}(i, t)$ denotes the market performance in GDP conditional on $\Omega_{-} \mathrm{t}$, the information set available in the current $\mathrm{t}$ period.

Positives values of $F_{-}(i, t)$ represent an unpredicted outperformance of the market in GDP terms in the next half year. Negative values of F_(i,t) an unexpected underperformance correction of the market predictions in GDP terms. F_ $(i, t: t)$ denotes the forecast error change in GDP growth for the periods $t$. The standard error term of the regression is $\varepsilon_{-}(\mathrm{i}, \mathrm{t})$.

Under the null hypothesis $\mathrm{H}_{-} 0$ that forecast expectation corrections have no impact on or relation with actual future market performance, the $\beta$-coefficient would be zero.

Data was retrieved from a European central bank's bi-annual GDP growth prospects. A regression to describe the relation of forecast error correction and actual market performance within the next half year $(t+1)$ over 35 data points reveals an overall fit with $\mathrm{R}$ square .147 and adjusted $\mathrm{R}$ square .096 of the model. The regression coefficient $\beta$-value of .348 for explaining the market performance in the 1 st period after the announcement of the correction is significant at the 5 percent one-sided t-testing level $\mathrm{t}=1.148$, with a $\mathrm{p}$-value of 0.039 . A one percentage point change in forecasting corrections is associated with a .348 percentage point change in GDP growth in the same direction in the first half year following the announcement.

The cyclical nature of markets become apparent in a second regression considering the long-term market performance based on equation 2 . The second regression was calculated based on the following equation 2 :

$$
\Delta \mathrm{Y} \_(\mathrm{i}, \mathrm{t}+2)=\alpha+\beta \_1 \quad \mathrm{~F} \_(\mathrm{i}, \mathrm{t}-1)+\beta \_2 \mathrm{~F} \_(\mathrm{i}, \mathrm{t})+\varepsilon_{-}(\mathrm{i}, \mathrm{t}) \text {, }
$$

(Equation 2)

whereby Y represents GDP and Y_(i,t:t+2) GDP growth in percent from the period $t+2$ starting from half a year until one year after the announcement.

Growth forecast corrections are calculated by the difference between actual real GDP percentage changes during one period $\mathrm{t}$, based on the latest data, minus the forecast prepared for the period under scrutiny presented in the previous period $t-1$. F_ $(\mathrm{i}, \mathrm{t})$ is the forecast error correction in GDP growth for the given periods of $t$. The associated forecast error correction is $F_{-}(i, t: t)=\left\{Y_{-}(i, t) \mid \Omega_{-} t\right\}$, where $Y_{-}(i, t)$ denotes the market performance in GDP conditional on $\Omega_{-} \mathrm{t}$, the information set available in the current $\mathrm{t}$ period.

Positives values of F_(i,t) represent an unpredicted outperformance of the market in GDP terms in the next half year. Negative values of F_(i,t) an unexpected underperformance correction of the market predictions in GDP terms. F_(i,t:t) denotes the forecast error change in GDP growth for the periods t. The standard error term of the regression is $\varepsilon_{-}(\mathrm{i}, \mathrm{t})$.

Under the null hypothesis H_0 that forecast expectation corrections have no impact on or relation with actual future market performance, the $\beta$-coefficient would be zero.

A regression to describe the relation of forecast error correction and actual market performance starting from half a year after the announcement up to a year after the announcement was calculated over 35 data points that reveals an overall fit with R square .414 and adjusted R square .378 of the model. The regression coefficient $\beta$-value of -.648 for explaining the market performance in the 2 nd period after the announcement of the correction is significant at the 5 percent one-sided t-testing level $t=-4.821$, with a $\mathrm{p}$-value of 0.000 . A one percentage point change in forecasting corrections is associated with a -.648 percentage point change in GDP growth in the same direction starting after the first half year after the announcement up to a year after the announcement. 
Overall, the history of past predictions and necessary corrections are positively correlated with future market performance for a half year and negatively associated for the period from half a year to a year after the announcement of a market prediction correction.

\section{Discussion}

In the literature, information is attributed to social power and societal status in social relations (Fowler et al., 1979). Language can change attitudes and information expression. Social exchange based on information was shown to be related to economic investment and transaction decisions shaping markets. Capitalist economies are characterized by some powerful long-term patterns in which order and disorder appear hand in hand. An economy's growth is expressed through recurrent fluctuations, punctuated by period depressions. Expectations about future market performances dominates these deeply rooted system dynamics. Dynamic expectations change substantially over time. While there is a wealth of knowledge on future discounting and market performance, hardly any information exists on retroactive expectation corrections' influence on market performance. This article is a first introduction to the idea of an influence of past market expectation corrections on market performance. Past prediction corrections were found to be highly significantly correlated in directionality and strength with aggregate market performance patterns. Past market performance comments were found to be systemically related to aggregate patterns of capitalist economies. The presented results are evidence for the equilibrating process in markets being inherently turbulent. Market outcomes are thereby portrayed as to be more than the sum of its parts, influenced by noise of corrections of past expectations. The interdependence of market actors in prices was shown to be biased by communication creating expectations but also expectation corrections.

The dataset presented is unique insofar as backtesting and reporting of market prediction corrections is not common with some key central banks. For instance, the German Deutsche Bank refrains from back-testing reporting. Yet the results presented offer invaluable insights into the relation of backwards corrections of expectations being systemically related to future performance. In the sense of Kahneman and Tversky's (1979) prospect theory, past losses loom in future performance.

In a wider scale, the results offer invaluable risk management tools in the age of globalization, which led to an intricate set of interactive relationships between individuals, organizations and states (Centeno \& Tham, 2012). Deepening nets of interactions challenge human foresight (Gilpin, 2001). As complex interdependencies may hold unknown outcomes for society, highly integrated international communities are under the whim of unexpected socioeconomic developments. In seeking to shed light onto implicit system failures' socio-economic consequences down the road and potentially-disastrous outcomes of cumulative actions triggering mass movements; the current results add to the currently emerging Emergent Risk Theory outlines unexpected dangers and insufficiently-described shadows of the invisible hand of the real competition world economy in the age of globalization (Centeno \& Tham, 2012; Miller \& Rosenfeld, 2010). This paper provided evidence for how market performance expectations and information about their burst may create risks within economic markets as for fueling economic booms and downturns. Drawing from heterodox socio-economic concepts such as George Soros' Theory of Reflexivity, data from a European central bank provided an in-depth understanding of how information flows echo in socio-economic correlates and may steer economic fluctuations has gained unprecedented momentum. New economic thinking widened the interdisciplinary lens to study emergent risks of international communication shadowing economic markets and the societal compound. In exceeding orthodox economics' insights and traditional public policy attempts to curb societal risks, heterodox economic approaches outlining socio-economics of crises appear as real-world relevant emergent risk prevention strategy. Applying real competition and reflexivity concepts but also the emergent risk theory onto economic fluctuations is an innovative heterodox way to explain how information creates economic ups and downs in a turbulent economic world (Held \& McGrew, 2007). The paper also adds to macroeconomic behavioral economics endeavors to explain the unplanned, uncoordinated and competitive nature of capitalist production as driver of economic crises. The article also provides evidence for how expectations of outcomes of multiple decisions among people with conflicting interests may not be foreseeable and therefore have been overlooked by stable equilibrium theories. Business cycle theories were sophisticated by empirical results in describing economic correlates of booms, allowing to derive inferences over irrational exuberance. Communication about markets and their performance was proven to be connected to long-term economic trends. The collective mood in society was put in relation to investment allocations amalgamating into economic trends that determine economic dynamisms of the collective soul of booms and busts. Economic forecasting and information about economic prospects have now to be shown how these indicators trickle down in individual economic decision making, which in its entirety shapes the economy as a whole. Access to information about market performance may also play a key 
role in price comparisons around the world, which are the basis of outsourcing and capital allocation decisions (Brenner, 2002).

Future direct implications would be to derive recommendation on specific information portrayed in media that can determine the investment mood and credit liquidity preferences of individuals and institutional representatives. Individual communication in the eye of economic ups and downs may in addition be the basis of social unrest and waves of strikes, which have been shown to be underlying factors determining wages and rates of profit for capitalist bleeding into economic cycles (Brenner, 2002). All these correlates set the tact in shaping economic booms and busts as well as the long term cycles. Concrete information and communication advice how to influence investment decisions may offer invaluable insights on how bubbles start and economic fluctuations can be smoothed.

As for future research implications, now that we have outlined that our past predictions' corrections are associated with actual performance, we need to better understand what specific market information can influence market performance. In the future, the concrete use of language as market control may be unraveled. A qualitative study of media contents could enlighten on the concrete and qualitative contents that make a market go up or under. Future prospective research could apply emergent risk theory onto economic fluctuations, which could serve as an innovative way to explain how and what information represented in the media creates economic fluctuations (Centeno et al., 2013). Linguistic analyses of newspaper articles about the economy could then shed light on how media representations and temporal foci echo in economic correlates and shape market outcomes. As business cycles are a collective phenomenon, group interactions' potential contribution to create business cycles could innovatively be captured in laboratory and field experiments on the role of information flows among groups in creating price expectations. Social discourse forms a social representation. Mapping out the systematic patterns of information flows' impact on economic correlates would allow predictions about processing and classifications of communication and aid explaining and interpreting economic transformation over time.

Newspaper are sites in which the views of various combinations of social forces and practices are articulated. Newspaper directly speak to the groups and organizations to which the readers belong, the institutions, movements and sections of society they identify. Information thereby shapes social perception. Using linguistic analysis as a way of uncovering the making of economic booms and busts will affect the general consciousness about language as an implicit economic correlate and basic of economic fluctuations. This could also lead to a richer understanding of the echo of market reporting on aggregate properties that give rise to stable aggregate patterns. Mass media providing a platform for social discourse to debate ideologies that presents information about what is happening, which gives rise to reinterpretation and an expectation in the market should become the study object of a follow up paper (Fowler et al., 1979). To determine the lexical variation and meanings embedded within different linguistic systems of expressing different ideologies or theories will aid to connect the linguistic structure with the social correlates of economic booms and busts. Evaluation of discourse could thereby enlighten on the process of economic formations based on herd mentality and swarm behavior.

Future work may study the linguistic processes to formulate the relation between economic fundamentals and economic outcomes through price. As a configuration of ideas and systems of reality, discourse is a pattern of categorization of complex information. Processes like interpretation, selection, abstraction are yet shunned from orthodox economic analyses. Further, we do not have information on correspondence and linguistic and theoretical processes in the price formation or how linguistic changes can manipulate economic outcomes. Linguistic transformation through focus in time appears important yet is to this day undescribed. The sequence of changes that create booms and busts but also the selection of wording of booms, busts and crises should therefore become subject to scrutiny. Linguistic changes that determinate theoretical and ideological significance could be studied, whereby linguistic discourse will become part of an economic analysis. All these endeavors would allow deriving cheap and easily implementable information nudges as countercyclical alleviation of economic frictions.

Since the production of text and the reception in terms of economic correlates are rather unstudied, we need an understanding how the nature of communicative events influences economic correlates, which may determine differences in economic power and status. Finding the linguistic structures that socialize market reactions will elucidate the role of information in the turbulent construction of the economy. Products of prevailing forms of economic and social organization will help reflect on how social processes and structures are related to material conditions.

The paper acknowledges the fact that there are different frameworks of interpretation in explaining economic long-term cycles. The societal influences of language on economic correlates should be studied in relation to communication's influence on society's ideological impress. How text embodies interpretations of subjects, evaluations of prices and relationships between the real economy and the financial community could be described in a qualitative study. As interpretative meanings are created uniquely in time, the systematic use of linguistic structures 
that is connected with the text's placement should become subject to scrutiny. As in each socio-economic system there is a social meaning to the natural language and economic communication, which is distinguished in its lexical and syntactic structures articulated; historical data but also cross-country datasets may reveal what communication facets are particular for a certain economic trend or economic market system. The linguistic structure of the economy and linguistic variations throughout different economic times will help describe how different economic outlooks or circumstances are portrayed and potentially perpetuated by the media.

How individuals' perceptions of the future and the state of the economy influence individuals' spending and investment choices may also have wider implications around the world. A future study on international differences could consolidate a global validity of the results but may also highlight different scenarios around the globe. In some countries, people may end up in an economically unfavorable situation through a self-fulfilling prophecy or selfenforcing mechanism. Developing nations with less fiscal space may face a vicious cycle transmitted through financial markets, where financial stress and macroeconomic self-enforcing feedback mechanisms eliminate the positive impacts of automatic market stabilizers (Semmler, 2013). Contractionary multipliers resulting from a reduction in fiscal spending, which recently gained attention of EU policymakers in the aftermath of the 2008/09 World Financial Crisis, may in particular imply negative effects in post-crisis economies (European Commission, 2014). Regime-dependent multiplies weaken economically already left-behind regions even more (Mittnik \& Semmler, 2012). How expectations and expectation corrections influence international trade around the globe could be another interesting extension of the first preliminary results.

Future studies may also investigate the temporal foci of communication strategies' impact on current decisions in order to unravel concrete strategies how market communication should be regulated. A future studies should outline the frequency of specific economic term references and distribution of active or passive, forward looking or backward thinking in relation to economic cycles. Since temporal foci were found to play a significant role in tax allocation preferences over time (Puaschunder \& Schwarz, 2012), temporal perspectives and temporal bundling strategies for the information sharing of important market prospects should be considered. Neutrality of communication contents should ensure a degree of certainty, continuity and universality to lower the perturbation biases as well as ideological governance decisions can create. The role of signaling and reputation information for the formation of expectation is another qualitative linguistic research area that could be addressed.

In the wider application, the results mirror the stylized fantasy of market predictions' reality being far from rational. Communicating expectation corrections gets re-packaged at the recipient, whose experience may influence their decision making and guide actions. Information on corrections may thus shape market outcomes in the sense of reflexivity. For linguistics, the study adds to the meaning and implicit meta-meanings of market prospects on economic correlates which are built upon receipt of messages. Unveiling the reality of communication as driver of economic ups and downs will aid deriving communication recommendations to ease economic fluctuations. Central planners but also journalists should be enabled to understand the economic ethos of words and the moral imperative of their economic coverage.

In this sense, access to market information determines the distribution of power within society. Central banker's privileged access to information but also governmental insights, technocrats' knowledge and media moguls control through language draw a hierarchy of those who hold information before it reaches the general populace. The implicit meaning of the results triggers us to re-evaluate economic systems for a democratization of information and derive concrete communication strategy recommendations. Central bankers could embrace a culture of an information fiduciary to responsibly communicate market information and control the potential fall out pro-actively. Leakage of sensitive information and fraud through insider trading based on information may be an essential boundary condition that deserves closer scrutiny in future work in this domain. Fake news and misleading information's emergent risk potential should become integrated into macroeconomic frameworks and legislative control should be adapted to the potential threat of new social media tools creating expectations. Due diligence of information provision and accuracy should become part of corporate governance frameworks and artificial intelligence ethics should embrace information quality control mechanisms in Fintech solutions. Nations around the world may imbue in the hallmarks of democracy and free markets the democratization of information meaning a fair and free access to accurate information to all presented in a cautious, informed and forward-thinking way. 


\section{References}

Arestis, Ph. \& Eatwell, J. (2008). Issues in Finance and Industry: Essays in Honour of Ajit Singh. New York, NY: Palgrave Macmillan.

Armstrong, Ph., Glyn, A. \& Harrison, J. (1991). Capitalism since 1945. Cambridge, MA: Basil Blackwell.

Benabou, R. \& Laroque, G. (1992). Using privileged information to manipulate markets: Insiders, gurus, and credibility. The Quarterly Journal of Economics, 107(3), 921-958.

Blanchard, O. \& Leigh, D. (2013). Growth and Forecast Errors and Fiscal Multipliers. Washington, D.C.: IMF Working Paper.

Brenner, R. (2002). The Boom and the Bubble: The US in the World Economy. New York, NY: Verso.

Brenner, R. (2006). The Economics of Global Turbulence: The Advanced Capitalist Economies from Long Boom to Long Downturn, 1945-2005. New York, NY: Verso.

Centeno, M. A., Cinlar, E., Cloud, D., Creager, A. N., DiMaggio, P. J., Dixit, A. K., Elga, A. N., Felten, E. W., James, H., Katz, St. N., Keohane, R. O., Leonard, Th. C., Massey, W. A., Mian, A. R., Mian, Z., Oppenheimer, M., Shafir, E. \& Shapiro, J. N. (2013). Global Systemic Risk. Unpublished manuscript for research community. Princeton, NJ: Princeton Institute for International and Regional Studies, Princeton University, April 2013.

Centeno, M. A. \& Tham, A. (2012). The Emergence of Risk in the Global System. Working paper, Princeton, NJ: Princeton University.

Dobb, M. H. (1929). A skeptical view of the theory of wages. Economic Journal, 39(156), 506-519.

European Commission (2014). Financial Crisis: Causes, Policy Responses, Future Challenges: Outcomes of EU-funded Research. EUR 26554 EN, Research and Innovation.

Fowler, R., Hodge, B., Kress, G. \& Trew, T. (1979). Language and Control. London, UK: Routledge.

Gilpin, R. (2010). Global Political Economy: Understanding the International Economic Order. Princeton, NJ: Princeton University Press.

Goodwin, R. M. (1967). A growth cycle. In Socialism, Capitalism and Economic Growth, ed C.H. Feinstein, Cambridge, UK: Cambridge University Press, pp. 54-58.

Held, D. \& McGrew, A. G. (2007). A New World Economic Order? Global Markets and State Power: Beyond Globalization/Anti-Globalization: Beyond the Great Divide. New York, NY: Polity.

Kahneman, D. \& Tversky, A. (1979). Prospect Theory: An Analysis of Decision under Risk. Econometrica, 47(2), $263-291$.

Keynes, J. M. (1936/2003). The General Theory of Employment, Interest and Money. Cambridge, MA: Harvard University Press.

Kwong, C. P. (2008). Mathematical Analysis of Soros's Theory of Reflexivity. Retrieved at https://www.researchgate.net/publication/23951999_Mathematical_analysis_of_Soros\%27s_theory_of_reflexivity

Leonhardt, J. M., Keller, L. R. \& Pechmann, C. (2011). Avoiding the risk of responsibility by seeking uncertainty: Responsibility aversion and preference for indirect agency when choosing for others. Journal of Consumer Psychology, 21(4), $405-413$.

Marx, K. (1867/1995). Capital: A Critique of Political Economy. Moscow, RU: Progress.

Miller, G. \& Rosenfeld, G. (2010). Intellectual hazard: How conceptual biases in complex organizations contributed to the crisis of 2008. Harvard Journal of Law and Public Policy, 33(2), 807-840.

Mittnik, St. \& Semmler, W. (2012). Regime dependence of the multiplier. Journal of Economic Behavior and Organization, 83(3), 502-522.

Okamoto, K. S. (2009). After the bailout: Regulating systemic moral hazard. UCLA Law Review, 57(1), 183-236.

Orwell, G. (1949). Nineteen Eighty-Four. New York, NY: Penguin.

Puaschunder, J. M. \& Schwarz, G. (2012). The Future is Now: How Joint Decision Making Curbs Hyperbolic Discounting but Blurs Social Responsibility in the Intergenerational Equity Public Policy Domain. Cambridge, MA: Harvard University Situationist Law and Mind Sciences Working Paper.

Schumpeter, J. A. (1949). Economic Theory and Entrepreneurial History. Cambridge, MA: Harvard University Press.

Semmler, W. (2013). The Macroeconomics of Austerity in the European Union. Social Research, 80(3), 883-914.

Sen, A. (2003). Sraffa, Wittgenstein, and Gramsci. Journal of Economic Literature, 16, 1240-1255.

Shaikh, A. M. (2010). Reflexivity, path dependence, and disequilibrium dynamics. Journal of Post Keynesian Economics, 33(1), 3-16.

Shaikh, A. M. (2013). On the role of reflexivity in economic analysis. Journal of Economic Methodology, 20(4), 439-445.

Shaikh, A. M. (2016). Capitalism: Competition, Conflict, Crises. Oxford, UK: Oxford University Press.

Soros, G. (1994). The Theory of Reflexivity. The MIT Department of Economics World Economy Laboratory Conference, Washington D.C. Retrieved at http://mertsahinoglu.com/research/the-theory-of-reflexivity-by-george-soros/

Soros, G. (2000). Open Society: Reforming Global Capitalism. New York, NY: Public Affairs.

Soros, G. (2003). The Alchemy of Finance. Hoboken, NJ: Wiley Finance.

Soskice, D. (1978) Strike waves and wage explosions, 1968-1970: An economic interpretation, In The Resurgence of Class Conflict in Western Europe since 1968, eds. C. Crouch \& A. Pizzorno, London, UK: Palgrave Macmillan, pp. $221-245$.

Stiglitz, J. E. (2006). Making Globalization Work. New York, NY: Norton.

Summers, L. H., \& Pritchett, L. (2012). Societies of the World: The Future of Globalization: Issues, Actors, and Decisions. Cambridge, MA: Harvard University Faculty of Arts and Sciences.

Urry, J. (2012). Complex Systems and Crises of Energy. Working paper. Lancaster, UK: University of Lancaster. 
von Weizsäcker, C. Ch. (2010). Cost-benefit Analysis with Adaptive Preferences. Bonn, Germany: Max Planck Institute for Research on Collective Goods. Retrieved at https://www.coll.mpg.de/download/Weizsaecker/Adaptive\%20Preferences.pdf

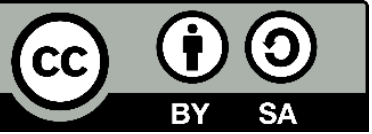

(C) 2019 by the authors. Licensee ACRN Publishing, Austria, Editor in Chief Prof. Dr. Othmar M. Lehner. This article is an open access article distributed under the terms and conditions of the Creative Commons Attribution (CC BY SA) license (https://creativecommons.org/licenses/by-sa/4.0/) 